\title{
Early findings: Food insecurity, obesity high in low-income Latino families
}

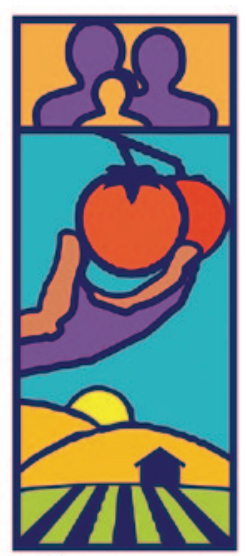
FAMILIA SANA
NIÑOS SANOS

$\mathrm{N}$

ew findings indicate the prevalence of food insecurity may be as high as $37 \%$ among lowincome, Mexican-origin farmworker families in California, say researchers analyzing early data in a 5-year UC study in Fresno County.

Data gathered in the first year of Niños Sanos, Familia Sana (Healthy Children, Healthy Family) form the baseline for a project under way in the Central Valley towns of Firebaugh and San Joaquin. The study is designed to reveal how best to prevent overweight and obesity in Mexican-origin children aged 3 to 7 years.

"Our data also show that $49 \%$ of the 3- to 7-yearolds in this group are overweight or obese," says Lucia Kaiser, UC Cooperative Extension specialist in the UC Davis Nutrition Department and a coinvestigator. "Several studies have reported a positive correlation between obesity and food insecurity in adults. These new findings underscore the urgency of addressing socioeconomic determinants in designing obesity prevention interventions for this population."

Funded by a $\$ 4.8$ million grant from USDA

National Institute of Food and Agriculture, the project involves a multidisciplinary team of UC Davis and Cooperative Extension (UCCE) investigators.

Previous economic research has shown that hunger rose sharply during the 2007-2008 recession. Although

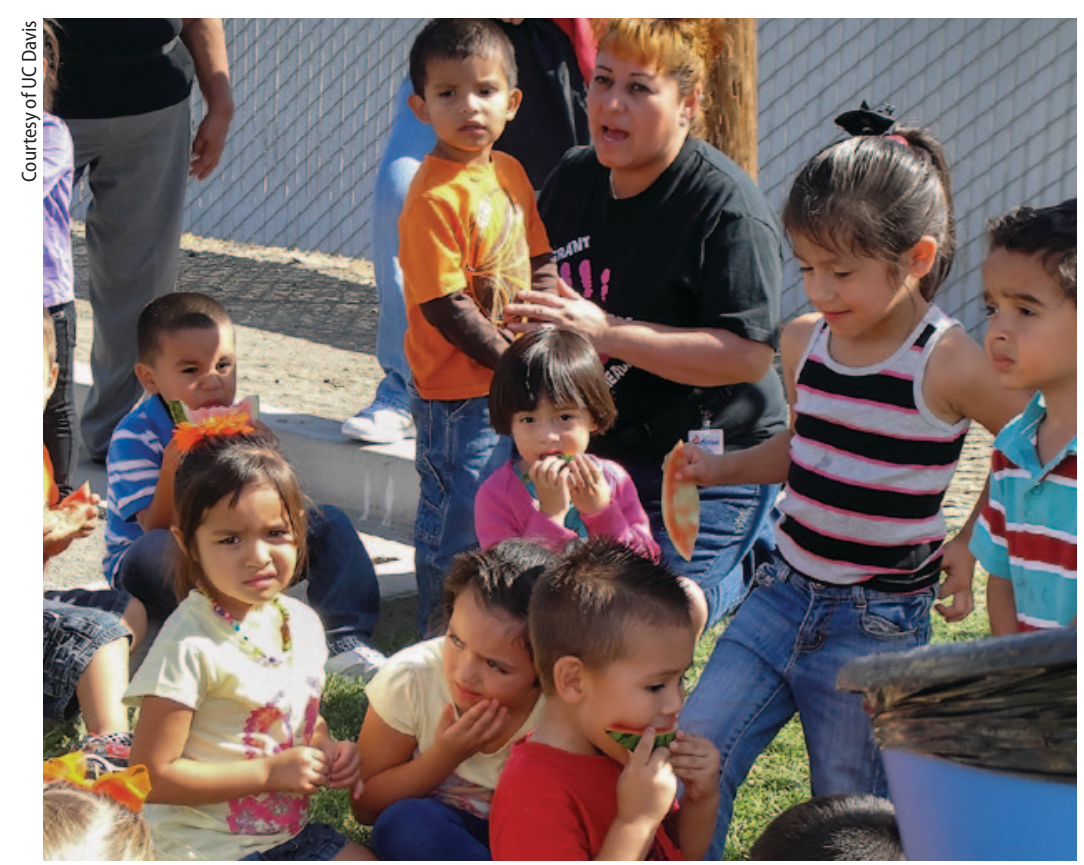

Kids and parents enjoy watermelon during a health fair in San Joaquin last summer. Researchers explained the project to members of the community and took measurements of children's height and weight.

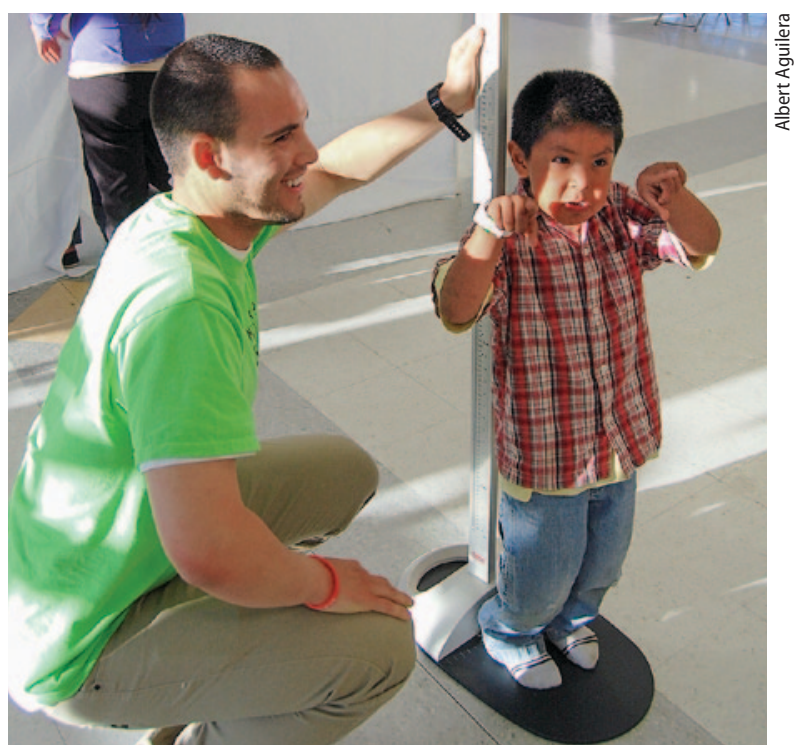

UC Davis student Ezequiel Valenga measures the height of a child during one of the data collection events in Firebaugh.

the recession officially ended in summer 2009, the number of households reporting food insecurity, both state- and nationwide, has changed little since then.

In September 2012, the U.S. Department of Agriculture's Economic Research Service (ERS) reported that California's overall rate of food insecurity is $16.2 \%$, significantly higher than the national average of $14.9 \%$. (ERS figures are based on 2011 data from a nationally representative sample.)

Households with very low food security constitute about $6 \%$ of the total, both state- and nationwide. That rate more than doubles among participants in the Niños Sanos, Familia Sana study. In the latter sample of 258 households, $13 \%$ reported very low levels of food security. (Very low food security refers to households reporting severe or child hunger; low food security refers to households reporting moderate or adult hunger.)

The UC Davis project is headed by Adela de la Torre, interim vice chancellor for student affairs. She is also an agricultural economist and faculty member of the UC Davis Department of Chicana/o Studies.

"More than four in every 10 children born to parents of Mexican heritage are overweight or obese and therefore at greater risk of early diabetes, high blood pressure and heart disease," said de la Torre. "We are fortunate that we have received unprecedented support to tackle this issue from community members, so that we can build a healthier environment in Firebaugh and San Joaquin." 
Niños Sanos, Familia Sana has a quasi-experimental design, Kaiser explained: one community, Firebaugh, was randomly assigned to receive the nutrition and economic incentive intervention and a comparison community, San Joaquin, to receive an educational program geared toward promoting academic success of Latino children.

The multidisciplinary UC team guiding this project includes 20 social scientists and other professionals, all working in partnership with parents and community members of Firebaugh and San Joaquin.

The Firebaugh program activities include:

- \$25 monthly in vouchers that can be used to buy fruits and vegetables at participating markets.

- Family nights that include parent education about children's nutrition needs and physical activity.

- Classroom instruction for children on nutrition and physical activity.

- Two health screenings yearly to monitor body mass index, skinfold thickness and waist circumference.

- A community art project with murals and posters promoting healthy eating and active living.

Concurrently, in San Joaquin, a similar number of children will receive the health screenings. In addition, their parents will be provided workshops on topics such as "How to support your children in school" and "Strategies to help your child prepare for college."

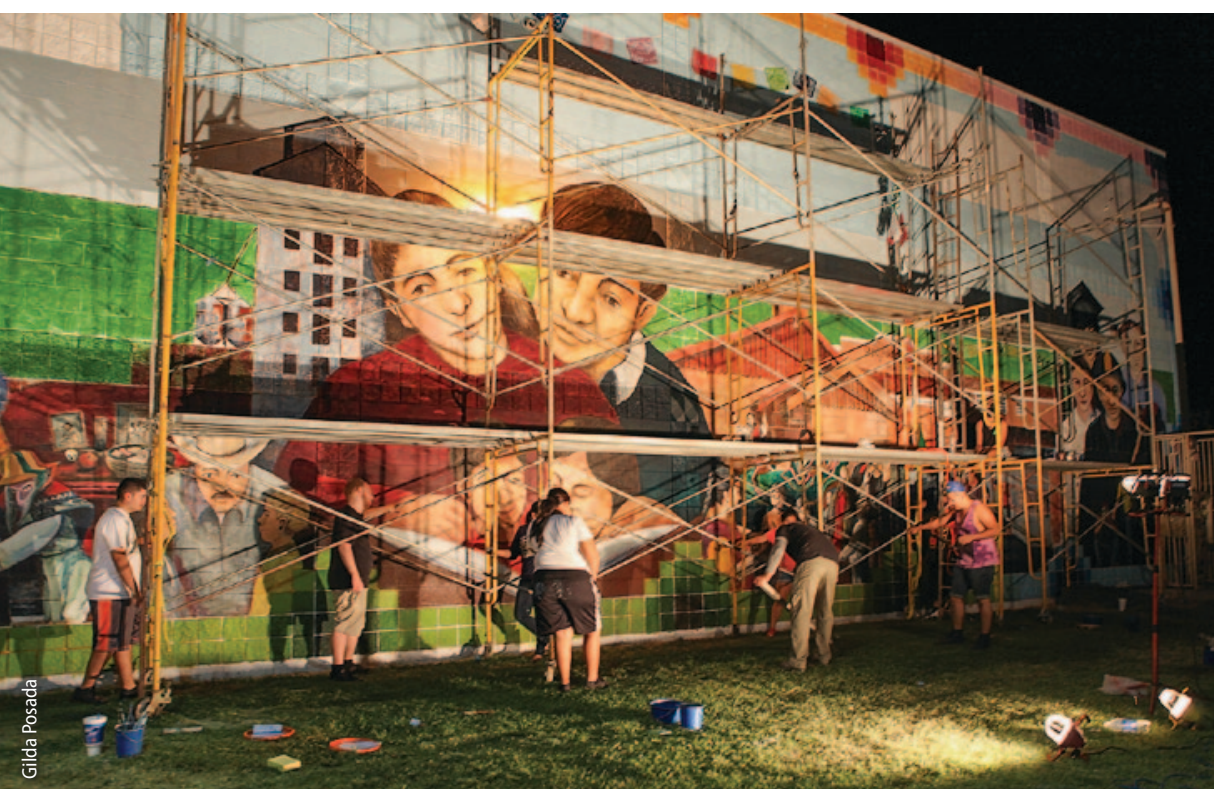

The Niños Sanos, Familia Sana mural in San Joaquin was painted by community members, and UC Davis faculty and students.

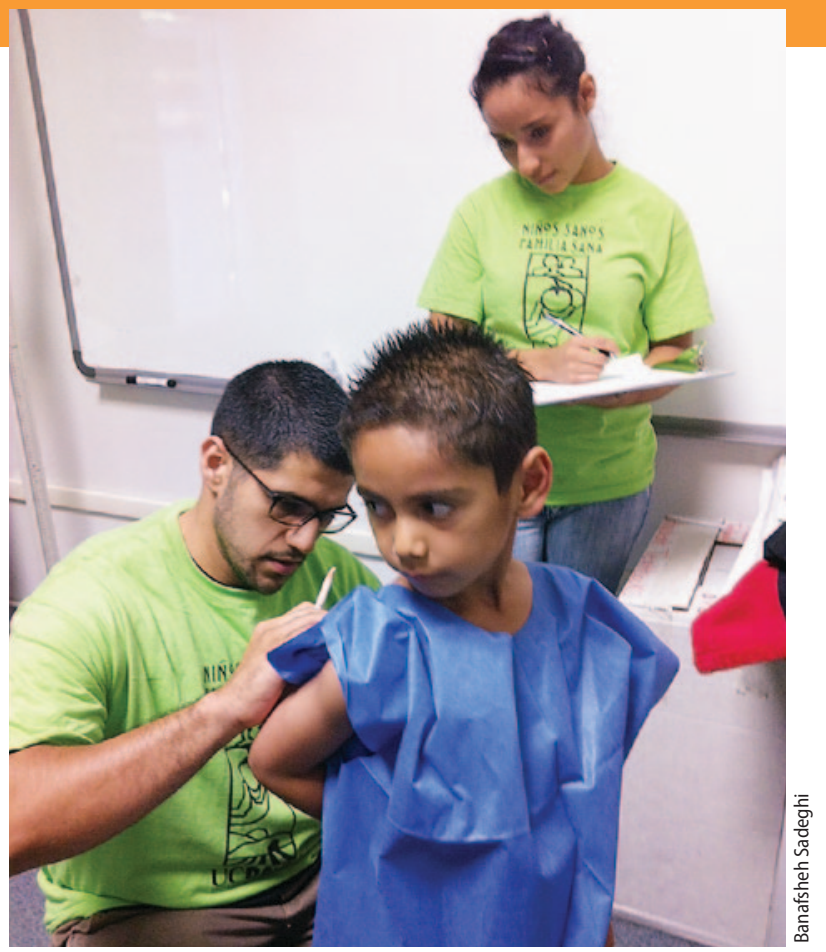

Graduate student Albert Aguilera and undergraduate Anahi Nunez complete measurements during data collection at Bailey Elementary in Firebaugh.

However, the San Joaquin group will not receive the more-intensive nutrition intervention. (After both towns had agreed to take part in the study, a random card draw determined that Firebaugh would be the intervention group and San Joaquin would be the control group.) At the study's end, UC Davis researchers will analyze the results to see which strategies worked best.

"This intervention study will be one of the first of its kind in the nation for Latino children between the ages of 3 and 8 and, hopefully, will help us target what really works in sustaining healthy eating and exercise for Latino families with young children," said de la Torre.

The programs will run for 3 years in these two Fresno County communities (with 2 additional years for baseline and followup data collection). UC nutrition specialist Kaiser noted that other goals of the project include 1) cultural adaptation of UCCE materials to prevent childhood obesity in Mexican-origin populations and 2) training of graduate and undergraduate students to increase cultural competency and ability to conduct community-based participatory research.

The Niños Sanos, Familia Sana team includes UC scientists, UC Cooperative Extension specialists and advisors, UC CalFresh in Fresno County, as well as other faculty and staff from the UC Davis Chicana/o Studies, Nutrition, and Agricultural and Resource Economics departments, the School of Education, and the Medical and Nursing schools in Sacramento.

Throughout the study, a community advisory committee consisting of school, community and parent representatives will meet regularly to provide feedback on program strategies, approaches, concerns and solutions to barriers. - Janet White 